\title{
Copla y supervivencia: Conchita Piquer, "Tatuaje", y el duelo de los vencidos ${ }^{1}$
}

\section{Coplas and Survival: Conchita Piquer, "Tatuaje", and the Mourning of the Defeated}

\author{
Stephanie Sieburth \\ Department of Romance Studies \\ Duke University. Durham. EE.UU.
}

\section{RESUMEN}

El presente estudio es una lectura de "Tatuaje" (1941), la copla más emblemática de Conchita Piquer, a la sombra de las fosas comunes del terror franquista. Numerosos intelectuales que crecieron durante la posguerra han dejado elocuente testimonio de la pasión con que los vencidos cantaban esta canción. Valiéndome de los recientes documentales que recogen el testimonio de los superviventes del terror franquista sobre el sufrimiento psicológico que supuso la prohibición de enterrar a sus familiares ni llevar a cabo ningún ritual de duelo por ellos, sostengo que "Tatuaje" tuvo tanto impacto porque funcionaba durante toda la posguerra como un ritual clandestino de duelo, un duelo bajo la clave de la historia de la mujer del puerto y su marinero. Interpreto la canción como una representación de, y terapia contra, el llamado "duelo complicado." Y argumento que "Tatuaje" también ayudó a los vencidos a resolver un problema existencial: el de ser fantasmas de una época anterior, de no tener papel en la "España nueva" franquista.

Palabras clave: Conchita Piquer; "Tatuaje"; Vencidos; Supervivencia; Duelo complicado; Ritual.

\section{SUMMARY}

The present study is a reading of "Tatuaje" (1941), the most famous copla of Conchita Piquer, in the context of Franco's mass graves. Several intellectuals who grew up during the postwar period in Spain have attested to the passion with which the defeated sang this song. The testimony of survivors of Franco's terror, presented in recent documentaries, describes the psychological suffering that resulted from the prohibition on burying their dead or carrying out rituals of mourning for them. I use this testimony to argue that "Tatuaje" had such a huge impact because it functioned during the entire postwar

${ }^{1}$ El presente texto forma parte de un libro, provisionalmente titulado Survival Songs: Conchita Piquer's Coplas and Franco's Regime of Terror. El manuscrito está bajo evaluación en la University of Toronto Press. 
period as a clandestine ritual of mourning, a mourning done in code under cover of the story of the woman at the port and her sailor. I interpret the song as a representation of, and as a therapy for, the condition called "complicated grief". And I argue that "Tatuaje" also helped the defeated to solve an existential problem: that of being ghostly carryovers from a previous era, without a role in Franco's "New Spain".

Key words: Conchita Piquer; "Tatuaje"; Defeated; Survival; Complicated Grief.

Este trabajo forma parte de un libro en el que analizo seis coplas de Concha Piquer como mecanismos de supervivencia en el contexto de la represión franquista. Actualmente, que yo sepa, no existe ningún libro académico completamente dedicado a la copla de posguerra. Y, en general, hacen falta más estudios sobre los mecanismos de supervivencia empleados en la posguerra que complementen el magnífico trabajo de los historiadores sobre las diversas formas de represión que intentaban aniquilar a los vencidos física o psicológicamente ${ }^{2}$. De los pocos estudios con que contamos sobre la copla, algunos son filológicos y otros versan sobre el uso de la copla en el cine de posguerra ${ }^{3}$. Mi trabajo representa un acercamiento distinto; es un intento de casar dos tipos de testimonios sobre los años cuarenta. En primer lugar, en los años setenta importantes intelectuales de la transición insistieron en que las canciones en general, y las coplas de la Piquer en particular, eran, en palabras de Carmen Martín Gaite, "enseres fundamentales para la supervivencia” durante la posguerra española (1990: 179)4. Manuel Vázquez Montalbán (2000: xx) decía que en un puñado de canciones de la época, todas de la Piquer, se encontraban huellas de la verdadera experiencia emocional del pueblo, e insistía en que estas canciones satisfacían necesidades auténticas de los oyentes. El segundo tipo de testimonios son los que han aparecido en las historias orales y los documentales producidos en la última década sobre los fusilamientos y las actuales exhumaciones de las fosas comunes. Estos testimonios recalcan el

${ }^{2}$ Ver, por ejemplo, Casanova (2002); Cenarro (2006); Juliá (1999); Richards (1998); Reig (1986); Rodrigo (2005).

${ }^{3}$ Emilio Alarcos Llorach (2006) hace un magistral estudio filológico de "Tatuaje." Josefa Acosta Díaz y otros (1997) han estudiado minuciosamente los tropos típicos de los poemas y canciones de Rafael de León. Jo Labanyi (2002) y Eva Woods (2003) han tratado el uso de las coplas en el cine. El estudio de Silvia Bermúdez (1997) se centra en "Tatuaje" desde la perspectiva de la rebelión sexual de la mujer protagonista, y desde la ausencia y la añoranza.

${ }^{4} \mathrm{La}$ voz en off de la película Canciones para después de una guerra (1971-76), de Basilio Martín Patino, declara, "Eran canciones para sobrevivir." 
terror continuo y el duelo bloqueado de los supervivientes de la represión franquista5.

Al ver la conexión que establecían Martín Gaite, Martín Patino y Vázquez Montalbán entre copla y supervivencia, tuve curiosidad por saber si esto era un decir, o si podía ser cierto que una canción podía tener efectos tan importantes como para afectar a la supervivencia. Al investigarlo, descubrí que la supervivencia puede depender tanto de factores psicológicos como de factores físicos y que, de hecho, no se pueden separar las dos cosas. Como es sabido, ciertos estados psicológicos suelen acarrear enfermedades físicas graves (Goleman 1995).

Por eso, cuando pensamos en la supervivencia de los vencidos en la posguerra, tenemos que preguntarnos no sólo cómo lograron sobrevivir en condiciones de persecución, hambre, epidemias, falta de calefacción, etc. También tenemos que pensar en cómo lograron sobrevivir llevando sobre los hombros unas cargas psíquicas tan pesadas que podrían acabar con cualquiera, incluso en situaciones de abundancia material. Estas cargas incluían: el terror continuo; el duelo bloqueado; el trauma; la falta de esperanza en el porvenir; y el silenciamiento con respecto a todos estos sentimientos tan intensos y tan dolorosos. Se puede afirmar que el silencio en sí constituía ya un peligro para la salud; se ha demostrado que reprimir emociones y guardar secretos traumáticos mina la resistencia del cuerpo a las enfermedades ${ }^{6}$.

Mi estudio analiza cómo cantar ciertas coplas compuestas por León y Quiroga e interpretadas por Conchita Piquer pudo ayudar a los vencidos a enfrentar estas dificultades psicológicas, alejando el peligro de dejar de sentir por completo y pasar por la vida como sonámbulos, lo que los psicólogos denominan "la muerte mental" (Ebert y Dyck 2004). Esto es lo que ocurre muchas veces cuando tenemos tanta pena o tanto miedo que nos desborda y ya no sentimos nada. Sostengo así que cantar las coplas de Rafael de León era casi la única manera que tenían los vencidos de expresar sus problemas en voz alta y en primera persona, sin correr peligro, porque lo hacían en clave, tomando el papel de los personajes ficticios encarnados de manera magistral por Concha Piquer. Un supuesto importante de este trabajo es que gran parte de este proceso de expresar las propias penas en clave de ficción era inconsciente. En el campo de la dramaterapia se ha demostrado que cuando representamos un papel, no tenemos que reconocer que las emociones dolorosas del personaje sean nuestras. Por lo tanto, nuestras

\footnotetext{
5 Armengou y Belis (2004); Silva (2005); Vinyes (2002); Semillas (2004); Victimas todavía (2003).

${ }^{6}$ Véanse Pennebaker y Sussman (1988); Pennebaker, Kiecolt-Glaser y Glaser (1988).
} 
defensas no se erigen para bloquear el dolor (Andersen-Warren y Grainger 2000: 87). De la misma forma, cuando lloramos por lo que le ocurre a un personaje de una película, podemos enfrentar sentimientos de pena profunda más fácilmente a través de la ficción, y no siempre somos conscientes de por qué lloramos.

Mi método es interdisciplinar, e involucra sobre todo a tres disciplinas. Primero, utilizo trabajos de psiquiatría y psicología clínica para entender mejor los procesos inconscientes que entran en funcionamiento cuando cantamos una canción. Esto en sí supone una novedad en el estudio de la música popular. En segundo lugar, utilizo los métodos literarios del comentario de texto para leer en profundidad la letra y la música de estas coplas, cosa que apenas se ha hecho hasta ahora, porque han sido clasificadas como "cultura popular" indigna de estudio. Y en tercer lugar, hago una lectura histórica, poniendo ciertas coplas de la Piquer en el contexto de las medidas concretas de la represión franquista de esos años, tal y como las conocemos ahora gracias a la labor de los historiadores y los periodistas.

Mi interpretación plantea una paradoja. Rafael de León y Concha Piquer estaban entre los vencedores. Ellos medraban en una España claramente dividida entre los que se consideraban seres humanos y ciudadanos "de orden," y los que el régimen definía como la "anti-España" y como "escoria”. ¿Cómo podía ser que unas canciones compuestas por los vencedores fueran de tanta utilidad para los vencidos? James Cone, autor de un libro sobre los espirituales cantados por los esclavos negros del Sur de EE. UU, dice que para que pudieran servir a la supervivencia de los oprimidos, las canciones tenían que tener una doble lectura: una lectura aceptable para los opresores, y otra que fuese útil para los oprimidos (Cone 1991: 28). Las coplas de Rafael de León podían tener diversas lecturas, como vamos a ver en el caso de "Tatuaje".

Los que recuerdan la época han dejado testimonios elocuentes sobre "Tatuaje". Francisco Umbral se refiere a ella como "la Quinta sinfonía callejera de la generación del piojo verde" (1987: 140). Carmen Martín Gaite evoca la "anestesia" de la posguerra, el clima de sordina, cómo la gente andaba de puntillas y evitaba evocar las heridas de la guerra. Y cómo de pronto, "como una ráfaga de sobresalto," irrumpía en la radio la voz sombría de Conchita Piquer cantando "Tatuaje." Dice Martín Gaite: "Aquello era contar una historia de verdad" (1990: 154). Y también recuerda, "Una pasión como aquella nos estaba vedada a las chicas sensatas y decentes de la nueva España". "Tatuaje," para ella, significaba volver a sentir plenamente, frente a la represión de los sentimientos imperante. Manuel Vázquez Montalbán interpreta esta copla como una canción de protesta de las mujeres contra una 
vida que consistía en hacer colas constantemente con la cartilla de racionamiento en la mano. Recuerda que "la cantaban con toda el alma aquellas mujeres de los años 40” (1986: 43). ¿Por qué ese enorme impacto? ¿Qué estaban expresando los vencidos cuando cantaban "Tatuaje" con toda el alma? ¿Qué decían a través de esta canción que no podían decir de otra manera?

Josefa Acosta Díaz, Manuel J. Gómez Lara y Jorge Jiménez Barrientos han publicado una colección de Poemas y canciones de Rafael de León, precedida de un estudio filológico detallado. En la introducción dicen algo con lo que discrepo profundamente. Dicen que Rafael de León "prescindió de la historia para ubicarse en el espacio intemporal del sentimiento" (Acosta y otros 1997: 11). El gran filólogo Emilio Alarcos Llorach también ha hecho una lectura ahistórica de la estructura de "Tatuaje". Los hispanistas que trabajan en el mundo anglosajón han preferido seguir la línea marcada por Manuel Vázquez Montalbán, quien en los años setenta afirmaba que estas coplas contenían huellas históricas muy importantes (Vázquez Montalbán 1997). El artículo de más envergadura sobre "Tatuaje" es el de Silvia Bermúdez, hispanista en la Universidad de California en Santa Bárbara, que lee esta copla como una subversión de las normas que el franquismo intentaba imponer en cuanto a la sexualidad de la mujer (Bermúdez 1997). El franquismo quería limitar el sexo al matrimonio y la iniciativa sexual al hombre (Mira Nouselles 2004). Frente a esto, "Tatuaje" presenta una mujer que toma la iniciativa sexual con el marinero, pidiéndole besos, aun sabiendo que está enamorado de otra. La protagonista, que marca su propio cuerpo con el tatuaje, se autodefine como un ser deseante, frente al modelo franquista de la mujer que deja que su marido la defina, tanto en lo sexual como en todo lo demás.

Bermúdez identifica la ausencia como un factor clave en esta canción, una ausencia del ser querido que marcaba la vida de los españoles de los años 40. Ella acentúa el aspecto sexual, el deseo creado por la ausencia de tantos esposos encarcelados, exiliados, o muertos. Yo voy a hacer una lectura complementaria a la de Silvia Bermúdez. Voy a hablar de "Tatuaje" como un ritual clandestino de duelo.

Para leer "Tatuaje" de esta manera, necesitamos entender ciertas cosas sobre la naturaleza del duelo. Hay que partir de que incluso en las circunstancias más normales, el duelo supone un trastorno completo en la vida del familiar que sobrevive. En casos normales, en los meses que suceden al fallecimiento, el superviviente pasará por etapas de negación, de añorar, buscar y soñar con el difunto, de llorar, de apartarse de la sociedad, antes de empezar poco a poco a aceptar la muerte del ser querido y a reestructurar su vida. Se establece que normalmente este proceso suele llevar un año y requiere muchísima energía psíquica (Sanders 1999: 63). 
Pero a veces el duelo se congela. El "duelo complicado" se diagnostica cuando a un año del fallecimiento del ser querido, el superviviente sigue siendo incapaz de aceptarlo, sufre intensamente, busca incesantemente al difunto, le añora. Pero al mismo tiempo, por evitar el dolor, procura evitar sitios o personas que le recuerden al difunto. Este proceso le impide funcionar normalmente en la vida diaria. El duelo complicado resulta mucho más probable después de muertes repentinas o violentas, como los fusilamientos del franquismo. Y el duelo complicado conlleva con frecuencia consecuencias físicas adversas; acrecienta la probabilidad de sufrir enfermedades cardíacas, cáncer, hipertensión y problemas psiquiátricos (Jacobs y Prigerson 2000; Prigerson 1997, 2002).

Ahora bien, había un aspecto de la represión franquista que casi garantizaba que el duelo de los vencidos se congelara. Me refiero a la prohibición de llevar a cabo ningún ritual de duelo por los fusilados. Los supervivientes muchas veces no tenían el cadáver, no sabían dónde estaba enterrado, a veces no sabían ni si su familiar estaba muerto o vivo. Las familias no podían velar el cuerpo, ni enterrarlo con los rituales correspondientes, ni vestirse de luto.

Los antropólogos señalan que los rituales de duelo tienen tres fases. La primera es la fase de separación, cuando el superviviente reacciona al fallecimiento, vela el cadáver, y lo entierra; es la fase de despedida. La segunda fase, la más larga, es la de transición. En las culturas primitivas se cree que el difunto tiene que hacer un largo viaje entre el mundo de los vivos y el de los muertos, pero el superviviente también está en una etapa de transición. Tanto el muerto como el vivo permanecen en un estado de limbo, entre la vida y la muerte. El familiar vivo se viste de luto, se abstiene de ciertas actividades sociales; no está viviendo ya su vida pasada con el difunto, pero tampoco la nueva vida que vendrá después. La tercera y última fase es la reincorporación social: ocurre cuando se está de "alivio" y se levanta el luto y las demás restricciones rituales y sociales. El superviviente se reintegra entonces a la sociedad (Van Gennep 1960; Robben 2004).

Yo me voy a concentrar en los problemas de la fase de transición, que es la más larga y la que creo que se escenifica en "Tatuaje". Existe una creencia ancestral, según la cual si el difunto no ha sido enterrado con las debidas ceremonias fúnebres, no puede entrar en el reino de los muertos y está condenado a errar sin sosiego, "como alma en pena," según la expresión popular. Hasta que el muerto no se haya enterrado, los vivos tampoco pueden descansar; de hecho, la necesidad de llevar a cabo rituales de duelo existe en todas las culturas humanas y en todos los tiempos (Doka 1989; Harrison 2003). Cuando el terror político hace imposible llevar a cabo los 
rituales de duelo, vemos, tanto en el caso español como en el caso del Holocausto, del GULAG, o de los desaparecidos por la dictadura argentina, que los familiares siguen intentando durante toda su vida localizar a sus familiares, exhumar los huesos y enterrarlos con los rituales normales. Sólo así podrán completar el proceso de duelo congelado desde hace décadas (Robben 2004c).

Si la necesidad de ritualizar el duelo es tan apremiante después de sesenta o setenta años, como estamos viendo hoy en España, nos podemos imaginar lo acuciante que habrá sido el impulso de llevar a cabo rituales fúnebres inmediatamente después de los fusilamientos. Pero eso era imposible. A partir de esta realidad, sostengo que cantar "Tatuaje" era para muchos vencidos un ritual clandestino de duelo que sustituía al ceremonial habitual que no podía llevarse a cabo $^{7}$.

Aunque muchos de los lectores conocerán de memoria la letra de "Tatuaje," la reproduzco aquí para analizar a continuación las múltiples posibilidades de comunicación que esta letra encierra.

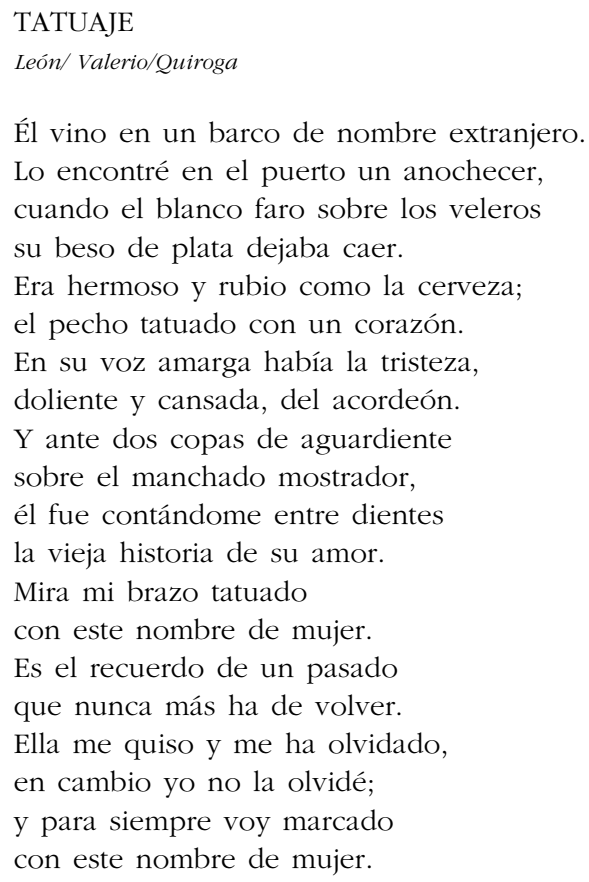

\footnotetext{
7 Esta lectura tiene como inspiración el uso de los rituales inventados como terapia en casos de duelo complicado. Véanse Rando (1993) y Van der Hart (1983). Cecilia Kohen (1988) utilizó rituales inventados para tratar a pacientes que sufrían problemas por el duelo complicado durante la dictadura argentina.
} 
Él se fue una tarde con rumbo ignorado en el mismo barco que lo trajo a mí; pero entre mis labios se dejó olvidado un beso de amante que yo le pedí.

Errante lo busco por todos los puertos; a los marineros pregunto por él, y nadie me dice si está vivo o muerto y sigo en mi duda buscándolo fiel. $\mathrm{Y}$ voy sangrando lentamente, de mostrador en mostrador, ante una copa de aguardiente donde se ahoga mi dolor. Mira tu nombre tatuado en la caricia de mi piel; a fuego lento lo he marcado y para siempre iré con él. Quizás ya tú me has olvidado, en cambio yo no te olvidé y hasta que no te haya encontrado sin descansar te buscaré.

Escúchame, marinero, y dime qué sabes de él; era gallardo y altanero y era más rubio que la miel. Mira su nombre de extranjero escrito aquí, sobre mi piel. Si te lo encuentras, marinero, dile que yo muero por él.

(C) Copyright 1941 Manuel López-Quiroga y Miquel, Rafael de León y Arias de Saavedra y Alejandro Rodríguez Gómez (Xandro Valerio), Madrid (España). Reservados todos los derechos.

Para leer "Tatuaje" como un ritual de duelo, hay que tener en cuenta que los rituales, para ser eficaces, necesitan introducir a los participantes en un espacio alternativo, alejado de la vida cotidiana, para que en ese espacio digan palabras y hagan gestos simbólicos que ayuden, en el caso que nos ocupa, a asimilar la pérdida del difunto. En la primera estrofa de "Tatuaje" León y Quiroga crean un espacio alternativo donde los vencidos podían enfrentar su propia situación de manera simbólica. Lo hacen en primer lugar por medio de la música, que empieza en tono mayor; la orquesta imita el ritmo de las olas. El oyente se pone a cantar con Piquer sin esfuerzo, arrullado por las olas. El tono menor y el dolor vendrán después, cuando ya esté preparado para entrar en ese terreno. 
Luego, como ha indicado Silvia Bermúdez, la canción tiene lugar en un escenario exótico: el puerto, ámbito asociado con el peligro y el deseo. El puerto es un lugar liminal, entre la tierra y el mar, casi imposible de vigilar, donde las leyes normales no se aplican del todo. La acción de "Tatuaje" comienza a una hora también liminal, el anochecer (Bermúdez 1997: 39, 47). Esta liminalidad, como veremos, refleja la situación psicológica de la protagonista. En la primera estrofa, Rafael de León introduce elementos que faltaban en la posguerra española, o que tenían que reprimirse. El "beso de plata" del faro evoca el sexo, prohibido o imposible por la ausencia del compañero. Tenemos la comida, presente también por medio de símiles en esta época de hambre (Graham 1995): el marinero es "rubio como la cerveza" o como la miel. Y se expresan sentimientos negativos y dolorosos, que normalmente tenían que ser reprimidos en la posguerra: el marinero tiene una voz "amarga", expresa "la tristeza doliente y cansada". Qué diferencia con la alegría constante exigida por el régimen. Carmen Martín Gaite recuerda la consigna de una escritora de novela rosa, Carmen de Icaza, portavoz de los ideales del régimen: "La vida sonríe a quien le sonríe, no a quien le hace muecas" (Martín Gaite 1990: 94). En el mundo alternativo de "Tatuaje," sin embargo, se puede expresar el dolor, la tristeza, la amargura, lo que verdaderamente sentían los vencidos. También en esta estrofa, tenemos la memoria de un "pasado que nunca más ha de volver." Esa memoria, la de un amor no correspondido, es tan indeleble como lo son, primero, las manchas del mostrador de la canción, y después el tatuaje, que precisamente no se puede borrar nunca. Así que en este espacio alternativo es donde se puede recordar el pasado que el franquismo busca borrar.

Veamos ahora cómo esta copla representa de manera magistral el tormento del duelo complicado. Hay una analogía entre la situación de la protagonista y la de los vencidos en este sentido. El marinero, el personaje al que más quiere nuestra protagonista, desaparece de la noche a la mañana, sin que ella sepa dónde está; lo mismo les ocurría a los familiares de las víctimas. La protagonista permanece aislada del resto de la sociedad, tomando una solitaria copa de aguardiente —al igual que muchos vencidos que no se atrevían a verse con sus antiguos compañeros republicanos, y que eran rechazados por los vencedores-. También, como su relación con el marinero no es legítima, es decir, reconocida por la sociedad, nadie apoya a la protagonista en su duelo. De la misma manera, al ser los vencidos definidos por los vencedores como infrahumanos, los franquistas no reconocían la necesidad del duelo por las víctimas, ni el derecho de los supervivientes a honrar a sus muertos. La protagonista va de puerto en puerto — de mostrador en mostrador-, intentando saber si su marinero está vivo o muerto, sin que nadie se lo diga. Lo mismo les ocurría a tantos y tantos vencidos 
que también iban de mostrador en mostrador, buscando información sobre sus familiares desaparecidos durante y después de la guerra.

La protagonista exhibe los síntomas más característicos del duelo complicado. Está constantemente preocupada por su marinero perdido. Su dolor sigue siendo tan fuerte como el día en que éste se fue; ella intenta disminuir la intensidad de su pena con el aguardiente. La protagonista pasa su vida errante, buscando al marinero. Como no lo puede recuperar, lo interioriza, imita su comportamiento, tomando aguardiente como él, queriéndole a él de la misma manera que él sigue queriendo a aquella otra mujer de su pasado, y tatuando su nombre en su cuerpo, igual que él había hecho con el nombre de la otra. La protagonista está entre viva y muerta, sangrando, muriendo por él.

Y no es casual que donde busque, errante, a su marinero sea de puerto en puerto. En la mitología clásica, es el agua lo que separa el reino de los vivos del de los muertos. En la Eneida de Virgilio, vemos las almas a orillas del río, con las manos extendidas, pidiéndole a Caronte que las lleve en su barca hasta el otro lado, al reino de los muertos. Pero las almas de los que no están enterrados están condenadas a vagar por esa ribera durante cien años antes de poder descansar ${ }^{8}$, y sus familiares vivos tendrán que penar también, hasta no conseguir enterrarlos. Este es el caso de la protagonista de "Tatuaje," que no tiene la seguridad de que su marinero esté muerto, y por lo tanto se ve obligada a vagar y buscar hasta encontrarlo. No puede llevar a cabo el proceso del luto, ni puede rehacer su vida, hasta no resolver la situación; por lo tanto, se ve condenada a un estado de limbo, de transición perpetua.

Ya he señalado que para poder funcionar como canción de supervivencia, las coplas debían de posibilitar una doble lectura. Si no hubieran tenido ingredientes aceptables para los vencedores, hubiera sido demasiado peligroso cantarlas. En este caso, la doble lectura que sirve para ocultar el sentido que estoy explicando tiene que ver con el marinero. "Tatuaje" se estrena en 1941. El marinero es extranjero, rubio, gallardo, altanero. La lectura más evidente es que se trate de un nazi; España está en plena germanofilia en este momento. Sin embargo, hay indicios que hacen posible otra lectura. El marinero es un hombre roto; sus sentimientos son de amargura, dolor, tristeza, cansancio, todo lo contrario de la ideología nazi y del optimismo que los nazis tendrían en 1941. Se abre, pues, la posibilidad de que el extranjero rubio evoque a los brigadistas internacionales, que también se fueron un día en barco para no volver.

\footnotetext{
${ }^{8}$ Virgilio, Aeneid, 1986: 154.
} 
Quisiera comentar ahora los versos siguientes:

Y nadie me dice
Si está vivo o muerto
Y sigo en mi duda buscándolo fiel.
Quizás ya tú me has olvidado
En cambio yo no te olvidé
Y hasta que no te haya encontrado
Sin descansar te buscaré.

Para entender el enorme impacto que tuvo esta canción, y para entender qué estaban expresando los vencidos cuando la cantaban con toda el alma, tenemos que preguntar: ¿Quiénes en la España de los años 40 podrían haber cantado estos versos, y a quiénes? Esta pregunta nos permite ver todo el dolor acumulado que se expresaba a través de "Tatuaje".

En el caso de los vencedores, hay que recordar a la División Azul, creada precisamente en 1941: hay franquistas que han mandado a sus hijos a Rusia y no saben si están vivos o muertos durante mucho tiempo.

Para los vencidos, hay muchas posibilidades dolorosas. Desde luego, los vivos podían cantar estos versos a los fusilados, afirmando que iban a seguir buscando hasta no encontrar sus restos. Otra posibilidad es que los que estaban fuera de la cárcel cantaran estos versos a los presos, que muchas veces estaban lejos, y en algunos casos sus familiares tampoco sabían dónde estaban. Los vencidos ahorraban dinero durante meses para viajar en autobús o en tren a una cárcel donde creían que estaba su familiar, para enterarse al llegar que lo habían trasladado a otra prisión, o, en el peor de los casos, para recibir la noticia de que le habían fusilado?. Y también podría ser que los que vivían el exilio interior cantaran esta copla pensando en los exiliados del extranjero, a los que muchas veces no podían escribir sin ponerles en peligro.

Una de las opciones más terribles tiene que ver con las presas a las que les habían quitado los hijos. Montse Armengou, Ricard Vinyes y Ricard Belis, en su libro y documental, Los niños perdidos del franquismo (2003), cuentan cómo para el jefe de los servicios psiquiátricos franquistas, Antonio Vallejo Nájera, el marxismo era una degeneración mental, sobre la que se podía actuar controlando el medio ambiente. Por lo tanto, era necesario criar a los hijos de los "rojos" lejos de sus padres. Según esta consigna se les quitaban los hijos a las madres presas cuando tenían tres años de edad. Otros niños perdidos, enviados a Francia u a otros países por sus padres republi-

\footnotetext{
${ }^{9}$ Esto es lo que le ocurre al personaje de Asunción en la novela de Antonio Ferres, Los vencidos, obra de 1960 que no fue publicada en España hasta el año 2005.
} 
canos durante la guerra para ponerles a salvo de los bombardeos, fueron secuestrados por agentes franquistas y no volvieron a ver a sus padres, sino que acabaron o en los orfanatos de Auxilio Social, o con familias franquistas. En 1941 una ley firmada por Franco permitió cambiar de apellidos a estos niños para que sus verdaderos padres no pudieran dar nunca con ellos. En un caso contado en el libro, dos hermanas separadas durante la guerra lograron encontrarse 60 años después gracias a un programa de televisión. Entonces, estas personas a las que se había cambiado la identidad o usurpado su maternidad o paternidad también cantarían, pensando en sus padres, en sus hijos, o en sus hermanos, "Quizás ya tú me has olvidado, En cambio yo no te olvidé, y hasta que no te haya encontrado, sin descansar te buscaré".

"Tatuaje" también ayudaba a los vencidos a enfrentar otro problema de supervivencia. Me refiero al problema existencial de encontrar sentido a la vida. Muchos habían perdido a sus seres más queridos. Los valores por los que habían luchado habían sido barridos de la vida pública. Muchos ya no podían ejercer su profesión, habiendo perdido gran parte de su identidad anterior a la guerra. Mucha gente sentía que su vida se había acabado con la derrota de la República. Y durante la posguerra iban a perder todavía más seres queridos a medida que Franco perfeccionaba su aparato de represión. Tenemos que recordar que, cuando fallece una persona querida, es muy normal, incluso en situaciones de libertad, creer que la vida no vale ya la pena y que no hay futuro. Pero en el caso de la posguerra española, la realidad objetiva confirmaba esa percepción, porque los vencidos no tenían grandes posibilidades de rehacer su vida, ni la afectiva ni la profesional. Entonces, ¿cómo no tirar la toalla? ¿Para qué vivir? Lo notable de "Tatuaje" es que logra no sólo representar ese dilema, sino también solucionarlo, construir una narrativa de futuro hecha precisamente del sufrimiento continuo que experimentaban tanto la protagonista como los vencidos ${ }^{10}$. Y aquí llegamos a la imagen central del tatuaje. La protagonista nos explica que ha diseñado su porvenir: se ha marcado con el tatuaje, y para siempre irá con él. Los verbos empiezan a ser de futuro: iré, buscaré. Lo que está tatuado es el nombre del marinero. La protagonista se ha encomendado una triple misión: recordar ese nombre; serle fiel (la palabra fiel es una de las palabras en las que se detiene la canción), y buscar a su marinero

\footnotetext{
${ }^{10}$ Viktor Frankl, en Man's Search for Meaning, sostiene que para sobrevivir en los campos de concentración nazis, un preso tenía que tener una misión de futuro que sólo él podía cumplir, como criar a un hijo o escribir un libro. Pero también tenía que poder otorgarle un sentido a su sufrimiento en el momento presente del campo (Frankl 1963: 115-127). "Tatuaje" logra cumplir con ambas condiciones.
} 
hasta encontrarlo. Estas decisiones son especialmente significativas en un régimen que intentaba acabar con la agencia individual, que quería un "silencio entusiasta" de la población, y que proclama, "Franco manda. España obedece".

Los vencidos pervivían en un régimen que les negaba cualquier papel de futuro. Pero cantando "Tatuaje," podían afirmar — bajo la clave de la historia de la mujer caída y su marinero- que seguían fieles a los que habían muerto, que eran testigos de ese "pasado que nunca más ha de volver," y que esas personas y ese pasado les habían marcado indeleblemente. Podían proclamar que, por intensa que fuera la represión, no lograría que olvidaran a los familiares y amigos que se les había arrancado tan injustamente.

Podemos ver el valor existencial de esta copla comparando el tatuaje de la protagonista de la copla con otro tatuaje que es un ejemplo terrorífico de cómo el régimen marcaba a sus víctimas. En el documental, Els nens perduts del franquisme, Teresa Martín habla de lo que vio de niña en casa de una vecina que había estado en la cárcel:

Y una vez en su casa... le enseñó a mi madre el pecho - y no era la únicacon el pecho izquierdo marcado a fuego con el yugo y las flechas. Perfectamente marcado. Y morado. Y eso sí que no se me olvida. Es una imagen que tengo grabada (Armengou y Belis 2003, 2 ${ }^{\mathrm{a}}$ parte).

Aquí vemos por qué es tan importante que en nuestra copla, la protagonista haya marcado el tatuaje en la piel por voluntad propia. Las atrocidades traumáticas consiguen grabar a fuego una memoria en el alma, y a veces en el cuerpo, de sus víctimas, sin su control y sin su consentimiento. El trauma es sinónimo de terror e indefensión. En "Tatuaje", sin embargo, el tatuaje que llevará la protagonista para siempre es el resultado de una decisión propia, es la afirmación de su voluntad de recordar para siempre precisamente el nombre de su marinero, representativo del nombre de cada uno de los fusilados y desaparecidos. La canción satisface de esta manera las condiciones psicológicas para la recuperación de un trauma: no basta simplemente con volver a experimentar las emociones de la vivencia traumática, sino que hay que reformular la experiencia, crear otras redes asociativas en el cerebro (Littrell 1998). Que es lo que hacían los vencidos cada vez que cantaban "Tatuaje" con Concha Piquer. De esta manera, "Tatuaje" toma el estado de limbo perpetuo en el que se encontraban los vencidos, y lo convierte en una afirmación de identidad, valores, y agencia, una misión de futuro.

"Tatuaje" era, así, una manera principal de romper el silencio sobre los 100.000 fusilados que yacían en fosas comunes que no se podían nombrar. También rompía el silencio sobre todos los demás ausentes, y sobre el su- 
frimiento y el dolor de los que quedaban. Al expresar en clave lo que de otra manera se silenciaba, esta copla ayudaba a aliviar el daño físico y psicológico de guardar secretos traumáticos. Y como texto repetido, siempre disponible en la radio, funcionaba como un ritual de duelo clandestino que podía ayudar a los vencidos a asimilar por lo menos parcialmente la pérdida de sus seres queridos. Un aspecto de la canción que les servía en esa tarea era la posibilidad de hablar directamente a los muertos, de decirles, no te he olvidado, te sigo buscando. En ese sentido, "Tatuaje" sirve como los poemas escritos a raíz del 11-S y del 11-M: en palabras de Steve Zeitlin, como un portal de comunicación directa con los muertos (2006: 106) $)^{11}$.

Recordar. Ser fiel. Buscar. La misión del protagonista de "Tatuaje" es idéntica a la misión de los familiares que hoy intentan exhumar, identificar, y enterrar los huesos de las víctimas en cementerios. Esto se pudo ver muy bien en las fotos que fueron proyectadas durante el concierto-homenaje a los republicanos organizado por la Asociación para la Recuperación de la Memoria Histórica en el $2004^{12}$. Primero, hay varias fotos en las que se ve una persona mayor junto a una fosa, enseñando las viejas fotos de los familiares que está buscando. En los años cuarenta, cada superviviente tenía su historia individual de duelo familiar que, al cantar "Tatuaje," se proyectaba en la historia de la protagonista y su marinero desaparecido. Hoy, cada persona mayor que vemos en las fotografías sostiene el retrato de un familiar fusilado, igual que la protagonista de "Tatuaje" lleva tatuado en la piel el nombre de su marinero. En las fotos, los familiares siguen con el duelo-

${ }^{11}$ Podemos entender mejor qué tipo de ritual de duelo era "Tatuaje", pensando en unos rituales que han aparecido en nuestros días. Después del 11 de septiembre, y de nuevo después del 11 de marzo, las calles de Nueva York y de Madrid se cubrieron de velas, de osos de peluche, de poemas, de objetos personales, de flores... El antropólogo Jack Santino llama a estos fenómenos "altares espontáneos." Son memoriales que combinan el duelo y la protesta. También existen para sustituir a los entierros que no se pueden realizar en estos casos atroces, porque no hay cadáveres. A diferencia de un entierro normal, sin embargo, los altares espontáneos están abiertos a todo el público, y lo involucran para que participe también en el ritual escribiendo poemas o dejando objetos a su vez (Santino 2006: introducción y capítulo 1; Senie 2006; Sánchez-Carretero 2011). En cuanto a los poemas que se escriben a los muertos, Steve Zeitlin ha mostrado que la función de esta poesía es manifestarles la despedida que no fue posible en vida por lo repentino e inesperado de las muertes. Otro aspecto clave de los altares espontáneos es que insisten en hacer presentes a los difuntos, llevando los memoriales al centro de la vida pública, a diferencia de otros fallecidos, apartados en un cementerio. Esto impide que sean borrados de la memoria. Véase Sánchez-Carretero (2006).

${ }^{12}$ El documental del concierto se encuentra en el CD/DVD, Recuperando Memoria (2004). 
protesta que ya expresaban en clave al cantar "Tatuaje". Siguen demostrando que recuerdan, siguen buscando, fieles a la memoria de las víctimas. Ahora por fin, pueden buscar y llorar de manera visible y directa.

Pero "Tatuaje" es un ritual no sólo individual, sino también colectivo. En otra de las fotografías del homenaje vemos las manos de tres personas sosteniendo una foto, y también un enorme collage de fotos de las víctimas. Estas imágenes nos recuerdan que "Tatuaje" también era una manifestación colectiva de duelo y de protesta; un ritual colectivo. Cuando una persona tenía una radio y cantaba "Tatuaje" con la Piquer, a veces los vecinos la oían por sus ventanas abiertas y la cantaban también. La copla se convertía entonces en el medio en que los vencidos podían decirse unos a otros que seguían vivos a pesar de todo, y que tenían una misión colectiva de seguir recordando a los muertos que llevaban tatuados en su alma y que ni el terror franquista podría borrar.

\section{BIBLIOGRAFÍA CITADA}

Acosta Díaz, J.; M. J. Gómez Lara y J. Jiménez Barrientos (eds.). 1997. Poemas y canciones de Rafael de León. $3^{\mathrm{a}}$. ed. Sevilla: Ediciones Alfar.

Alarcos Llorach, E. 2006. "Tatuaje: Un acercamiento a la copla". Clarin 65: 3-11.

Andersen-Warren, M. y R. Grainger. 2000. Practical Approaches to Dramatherapy: The Shield of Perseus. Londres: Jessica Kingsley Publishers.

Armengou, M. y R. Belis 2003. Les fosses del silenci. Part 2. DVD. Enciclopedia Catalana and Televisió de Catalunya.

Armengou, M. y R. Belis 2003. Els nens perduts del franquisme. Parts 1 and 2. DVD. Enciclopedia Catalana and Televisió de Catalunya.

Armengou, M. y R. Belis 2004. Las fosas del silencio: ¿Hay un holocausto español? Barcelona: Plaza y Janés.

Bermúdez, S. 1997. "Music to My Ears": Cuples, Conchita Piquer, and the (Un)making of Cultural Nationalism". Siglo XX/20 th Century 15 (1-2): 33-54.

Casanova, J. 2002. "Una dictadura de cuarenta años", en J. Casanova (ed.), Morir, matar, sobrevivir. 3-52. Barcelona: Crítica.

Cenarro Lagunas, A. 2006. La sonrisa de Falange: Auxilio Social en la guerra civil y en la posguerra. Barcelona: Crítica.

Colmeiro, J. F. 2005. Memoria histórica e identidad cultural: De la postguerra a la postmodernidad. Barcelona: Anthropos.

Cone, J. H. 1991. The Spirituals and the Blues: An Interpretation. Nueva York: Orbis Books.

Doka, K. J. 1989. "Disenfranchised Grief", en K. J. Doka, Disenfranchised Grief: Recognizing Hidden Sorrow: 3-12. Lexington, MA: Lexington Books.

Ebert, A. y M. J. Dyck. 2004. "The experience of mental death: The core feature of complex posttraumatic stress disorder". Clinical Psychology Review 24: 617-635.

Ferres, A. 2005. Los vencidos. Madrid: Gadir.

Frankl, V. 1963. Man's Search for Meaning: An Introduction to Logotheraphy. Nueva York: Pocket Books. 
Gennep, A. van. 1960. The Rites of Passage. Chicago: The University of Chicago Press. Goleman, D. 1995. Emotional Intelligence. Nueva York: Bantam.

Graham, H. 1995. "Popular Culture in the Years of Hunger", en H. Graham y J. Labanyi (eds.), Spanish Cultural Studies. An Introduction: 237-245. Oxford: Oxford University Press.

Harrison, R. P. 2003. The Dominion of the Dead. Chicago-Londres: University of Chicago Press.

Horowitz, M. J., y otros. 1997. "Diagnostic Criteria for Complicated Grief Disorder". American Journal of Psychiatry 154 (7): 904-10.

Jacobs, S. y H. Prigerson. 2000. "Psychotherapy of Traumatic Grief: A Review of Evidence for Psychotherapeutic Treatments". Death Studies 24 (6): 479-95.

Juliá, S. (ed.). 1999. Victimas de la Guerra Civil. Madrid: Temas de Hoy.

Kohen, C. 1988. "Political Traumas, Oppression, and Rituals", en E. Imber-Black, J. Roberts y R. Alva Whiting (eds.), Rituals in Families and Family Therapy: 363-383. Nueva York: W. W. Norton \& Co., Inc.

Labanyi, J. 2002. "Musical Battles: Populism and Hegemony in the Early Francoist Folkloric Film Musical", en J. Labanyi (ed.), Constructing Identity in Contemporary Spain: 206221. Nueva York: Oxford University Press.

Littrell, J. 1998. "Is the Reexperience of Painful Emotion Therapeutic?". Clinical Psychology Review 18 (1): 71-102.

Martín Gaite, C. 1990. El cuarto de atrás. Madrid: Ediciones Destino.

Martín Patino, B. 2003 [1971]. Canciones para después de una guerra. DVD. Diario El País.

Mira Nouselles, A. 2004. De Sodoma a Chueca: Una historia cultural de la homosexualidad en España en el siglo XX. Barcelona: Editorial Egales.

Pennebaker, J. W. y J. R. Sussman. 1988. "Disclosure of Traumas and Psychosomatic Process". Social Science and Medicine 26: 327-332.

Pennebaker, J. W.; J. K. Kiecolt-Glaser, y R. Glaser. 1988. "Disclosure of Trauma and Immune Function Health Implications for Psychotherapy". Journal of Consulting and Clinical Psychology 56 (2): 239-245.

Prigerson, H. G., y otros. 1997. "Traumatic Grief as a Risk Factor for Mental and Physical Morbidity". American Journal of Psychiatry 154 (5): 616-23.

Prigerson, H. G., y otros. 2002. "Rates and Risks of Complicated Grief among Psychiatric Patients in Karachi, Pakistan". Death Studies 26 (10): 781-92.

Rando, T. A. 1993. Treatment of Complicated Mourning. Champaign, IL: Research Press. Recuperando memoria: Concierto-Homenaje a los Republicanos. 2004. Dir. Diego Sabanés. Prod. Contamíname Discos. DVD and CD. El Diablo Distribución.

Reig Tapia, A. 1986. Ideología e historia: Sobre la represión franquista y la Guerra Civil. Madrid: Akal.

Richards, M. 1998. A Time of Silence: Civil War and the Culture of Repression in Franco's Spain, 1939-1945. Nueva York: Cambridge University Press.

Robben, A. C. G. M. (ed). 2004a. Death, Mourning, and Burial: A Cross-Cultural Reader. Malden, MA: Blackwell.

Robben, A. C. G. M. 2004b. "Death and Anthropology: An Introduction", en A. Robben (ed.), Death, Mourning, and Burial: A Cross-Cultural Reader: 1-16. Malden, MA: Blackwell. 
Robben, A. C. G. M. 2004c. "State terror in the Netherworld: Disappearance and reburial in Argentina", en A. Robben (ed.), Death, Mourning, and Burial: A Cross-Cultural Reader: 134-148. Malden, MA: Blackwell.

Rodrigo, J. 2005. Cautivos. Campos de concentración en la España franquista, 1936-1947. Barcelona: Crítica.

Sánchez-Carretero, C. 2006. "Train of Workers, Trains of Death: Some Reflections after the March 11 Attacks in Madrid", en J. Santino (ed.), Spontaneous Shrines and the Public Memorialization of Death: 333-347. Nueva York: Palgrave and MacMillan.

Sánchez-Carretero, C. (coord.). 2011. El Archivo del Duelo. Análisis de la respuesta ciudadana ante los atentados del 11 de marzo en Madrid. Madrid: CSIC.

Sanders, C. M. 1999. Grief: The Mourning After: Dealing with Adult. Bereavement. 2. ${ }^{\mathrm{a}}$ ed. Nueva York: John Wiley \& Sons.

Santino, J. (ed.). 2006. Spontaneous Shrines and the Public Memorialization of Death. Nueva York: Palgrave and MacMillan.

Semillas. 2004. Dir. D. Sabanés. Recuperando memoria: Concierto-Homenaje a los Republicanos. Prod. Contamíname Discos. DVD. El Diablo Distribución.

Senie, H. F. 2006. "Mourning in Protest: Spontaneous Memorials and the Sacralization of Public Space", en J. Santino (ed.), Spontaneous Shrines and the Public Memorialization of Death: 41-56. Nueva York: Palgrave and MacMillan.

Silva, E. 2005. Las fosas de Franco: Crónica de un desagravio. Madrid: Temas de Hoy.

'Tatuaje.' Lo mejor de Conchita Piquer. 1987. Madrid: EMI-Odeón.

Umbral, F. 1987. Memorias de un hijo del siglo. Madrid: Ediciones El País.

Van der Hart, O. 1983. Rituals in Psychotherapy. Nueva York: Irvington Publishers.

Vázquez Montalbán, M. 1986. Crónica sentimental de España. Madrid: Espasa-Calpe.

Vázquez Montalbán, M. 1997. Tatuaje. Barcelona: Planeta.

Vázquez Montalbán, M. 2000. Cancionero general del franquismo, 1939-1975. Barcelona: Crítica.

Víctimas todavía. 2003. Dir. J. Sánchez Martínez y P. Sánchez Torres. Prod. A. Quílez Tomás and Castilla-La Mancha Noticias SL. Collifilms Diffusion.

Vinyes, R.; M. Armengou y R. Belis. 2002. Los niños perdidos del franquismo. Barcelona: Plaza \& Janés Editores.

Virgilio. 1986. Aeneid. Trans. C.H. Sisson. Manchester: Carcanet.

Woods, E. M. 2003. "Excess, Affect and Emergent Classes: Melodramatic Modes in Mariquilla Terremoto (Benito Perojo 1939) and Filigrana (Luis Marquina 1949)". Letras Peninsulares 16: 291-315.

Zeitlin, S. 2006. "Oh Did You See the Ashes Come Thickly Falling Down? Poems Posted in the Wake of September 11", en J. Santino (ed.), Spontaneous Shrines and the Public Memorialization of Death: 99-111. Nueva York: Palgrave and MacMillan.

Fecha de recepción: 23 de mayo de 2011

Fecha de aceptación: 19 de julio de 2011 